Tạp chí Khoa học và Công nghệ biển T12 (2012). Số 2. Tr 64 - 76

\title{
TUỔI VÀ SINH TRƯỞNG CỦA CÁ MIỄN SÀNH GAI (EVYNNIS CARDINALIS LACEPÈDE, 1802) Ở VÙNG BIỂN PHÍA TÂY VỊNH BẮC Bộ
}

\author{
TRÀN VĂN CƯờnG
}

Viện Nghiên cứu Hải sản

\begin{abstract}
Tóm tắt: Tuổi và sinh truởng của cá miễn sành hai gai ở vịnh Bắc bộ được xác định bằng cách đếm các vòng năm trên nhĩ thạch thu thập trong giai đoạn tì̀ năm 2009 đến 2011. Kết quả nghiên cứu đã chỉ ra rằng, nhĩ thạch của cá miễn sành hai gai có kich thước lớn. Vòng năm trên nhĩ thạch thể hiện tuoong đối rõ ràng. Cá thể lớn nhất bắt gặp thuộc nhóm tuổi $6^{+}$. Cấu trúc tuổi của đàn cá chủ yếu tập trung ở nhóm tuổi $0^{+}$đến tuổi $2^{+}$. Phuơng trình sinh truởng von Bertalanffy của cá miễn sành hai gai được xác định nhu sau:
\end{abstract}

$F L=28,66 *\left(1-e^{\left(-0,257^{*}(t-(-1,08))\right)}\right)$.

Tù khóa: Cá miễn sành hai gai, Evynnis cardinalis, tuổi và sinh truởng, vịnh Bắc bộ.

\section{MỞ ĐÀ̀U}

Cá miễn sành hai gai là loài cá rạn, thường sống ở vùng nước có độ sâu từ $0-100 \mathrm{~m}$ (Chen, Qui, 2005; Masuda et al., 1984). Vùng phân bố địa lý của loài cá này tập trung ở phía Tây Thái Bình Dương bao gồm vùng biển phía Đông, phía Nam Trung Hoa và một phần vùng biển phía Bắc của Philippins (Eggleston, 1974). Ở Việt Nam, cá miễn sành hai gai phân bố chủ yếu ở vịnh Bắc bộ (Nguyễn Hữu Phụng et al., 1995) và góp phần quan trọng đối với nguồn lợi nguồn lợi hải sản ở vùng biển này (Phạm Thược et al., 1977). Sản lượng đánh bắt của loài chiếm tỷ lệ cao trong tổng sản lượng khai thác ở nghề lưới kéo đáy, đặc biệt là ở mùa gió Tây Nam (Phạm Thược et al., 1977; Đào Mạnh Sơn, 2001; Chu Tiến Vĩnh, 2002; Vũ Việt Hà, 2008).

Nghiên cứu sinh trưởng và xác định các tham số chủng quần là cơ sở đầu vào cho các mô hình đánh giá nguồn lợi. Đối với cá miễn sành hai gai, nghiên cứu sinh trưởng của quần thể loài cá này tập trung chủ yếu ở một số vùng thuộc biển Nam Trung Hoa (Zhang, Zhang, 1983; Chu Tiến Vĩnh, 2002; Chen, Qui, 2003; Ye, 2004; Hou et al., 2008).

Ở vịnh Bắc bộ, các nghiên cứu về sinh trưởng của cá miễn sành hai gai đã công bố tập trung ở vùng biển phía Đông (phía Trung Quốc) theo phương pháp trực tiếp đọc tuổi trên nhĩ thạch (vảy) và gián tiếp từ phân tách tần suất chiều dài (Chen, Qui, 2003; Hou $e t$ al., 2008). Năm 2002, các tham số sinh trưởng của loài cá này ở vùng biển phía Tây (phía 
Việt Nam) lần đầu tiên được xác định với phương pháp gián tiếp từ phân tích tần suất chiều dài (Chu Tiến Vĩnh, 2002). Đến nay, chưa có nghiên cứu về tuổi và sinh trưởng bằng phương pháp trực tiếp cho đối tượng này ở vùng biển phía Tây vịnh Bắc bộ.

Với tổng số 174 mẫu nhĩ thạch của cá miễn sành hai gai được thu thập và phân tích, bài viết này sẽ trình bày kết quả nghiên cứu tuổi và sinh trưởng của loài cá này ở vùng biển phía Tây vịnh Bắc bộ. Kết quả nghiên cứu sẽ cung cấp các tham số đầu vào cho các mô hình đánh giá nguồn lợi, làm cơ sở đề xuất giải pháp quản lý, bảo vệ và phát triển hợp lý nguồn lợi đối tượng này.

\section{TÀI LIỆU VÀ PHƯƠNG PHÁP}

\section{Tài liệu nghiên cứu}

thập trên tàu điều tra lưới kéo đáy đơn cá ở vùng đánh cá chung vịnh Bắc bộ. Ngoài ra, mẫu thu bổ sung tại bến cá Máy Chai, Cát Bà (Hải Phòng) và Lạch Cờn (Nghệ An) (hình 1). Tổng số 174 mẫu nhĩ thạch cá đã thu thập, phân tích và xác định tuổi.

\section{Phương pháp nghiên cứu}

Thu mẫu và phân tích nhĩ thạch cá được thực hiện theo hướng dẫn của Stevenson và Campana (1992). Mẫu nhĩ thạch của cá miễn sành hai gai được thu thập theo nhóm chiều dài cơ thể. Số lượng mẫu cho mỗi nhóm chiều dài tối thiểu 10 mẫu. Đối với các cá thể có kích thước lớn, do ít bắt gặp nên số mẫu thu thập

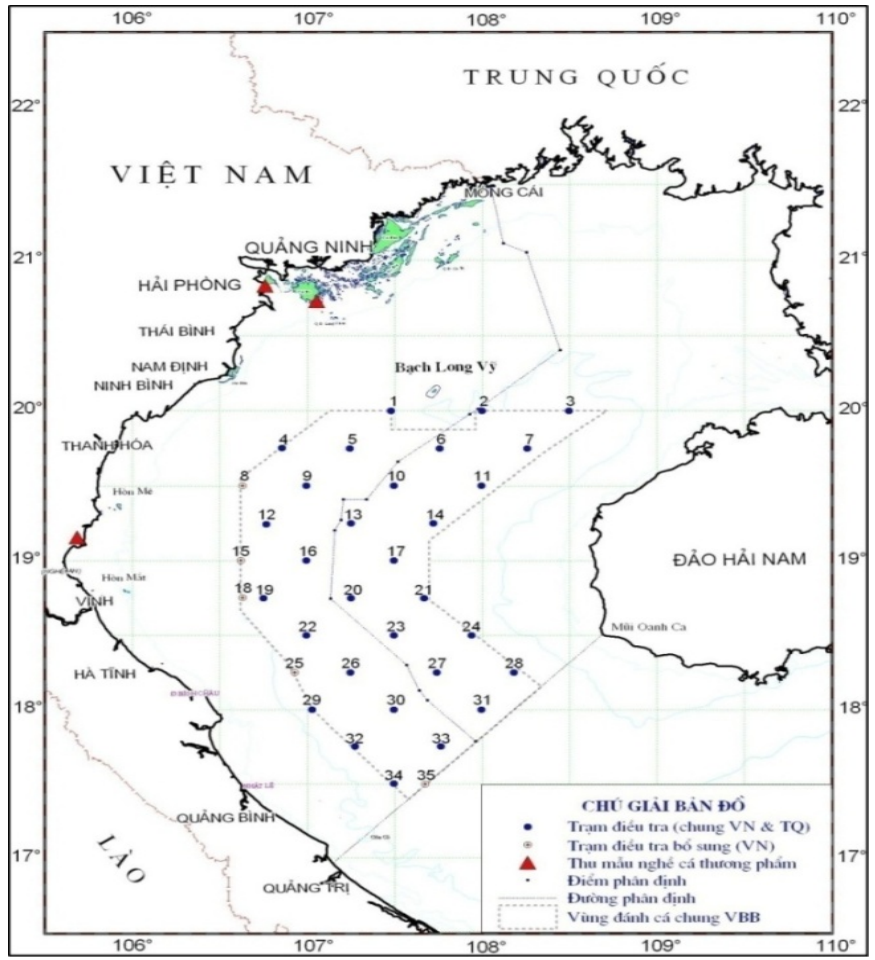

Hình 1: Sơ đồ trạm điều tra và điểm thu bổ sung tại các bến cá phụ thuộc vào tình hình thực tế. Nhĩ thạch được lấy mẫu, vệ sinh sạch bằng nước cất, ghi nhãn thông tin (vị trí thu mẫu, thời gian, chiều dài FL, khối lượng, giới tính) và bảo quản bằng cồn tuyệt đối $95 \%$.

Nhĩ thạch được gắn cố định vào lam kính bằng nhựa Crystal Bond. Nhĩ thạch được cắt bằng máy Isomet 1000 , mài trên giấy cát ở các độ nhám khác nhau và giấy bóng bằng máy mài Phoenix Beta (hình $2 \mathrm{a}$ ). Quan sát nhĩ thạch, xác định tuổi cá và chụp ảnh bằng 
kính hiển vi soi nổi Nikon SMZ 1500 ở các độ phóng đại khác nhau (10X-110X) có gắn trực tiếp máy ảnh Nikon DS-Ri1 (hình 2b).

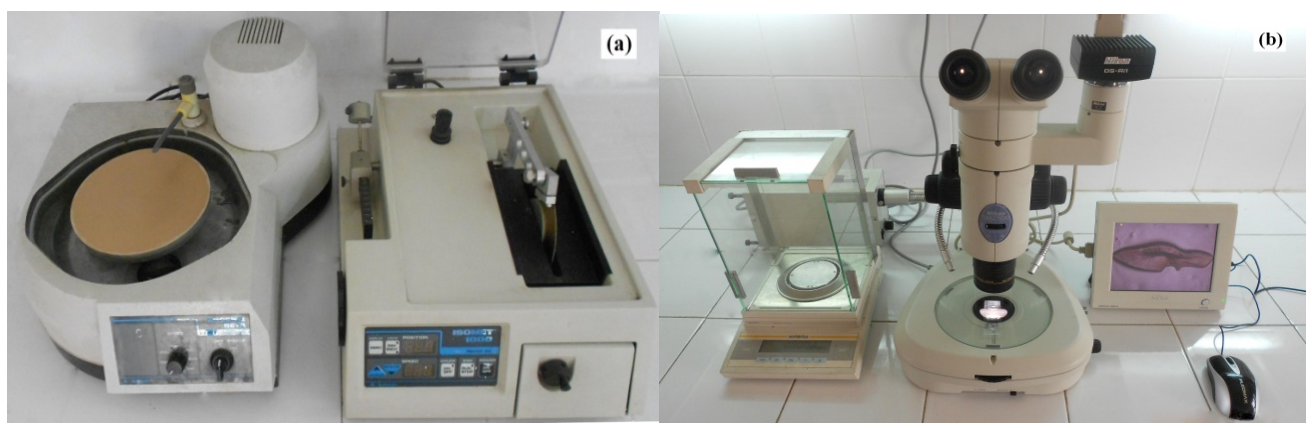

Hình 2: Thiết bị sử dụng trong nghiên cứu xác định tuổi cá bằng nhĩ thạch

Đo chiều dài $(\mathrm{OL})$, chiều rộng $(\mathrm{OWi})$, bán kính nhĩ thạch $(\mathrm{R})$ và bán kính các vòng năm $\left(\mathrm{r}_{1}, \mathrm{r}_{2} \ldots \mathrm{r}_{\mathrm{n}}\right)$ trên nhĩ thạch bằng phần mềm Image Pro Plus 6.0 (hình 3). Cân khối lượng nhĩ thạch bằng cân điện tử với độ chính xác $0,001 \mathrm{~g}$ (hình 2 ).

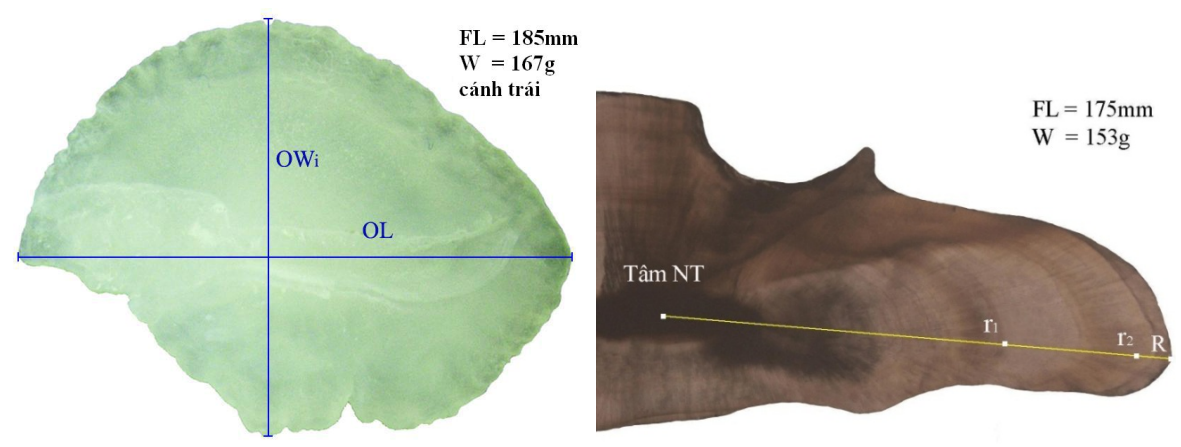

Hình 3: Phương pháp đo kích thước và bán kính $\left(\mathrm{R}, \mathrm{r}_{1}, \mathrm{r}_{2} \ldots\right)$ nhĩ thạch

\section{Phưong pháp xủ̉ lý số liệu}

Tuổi của cá được xác định bằng cách xem các vòng năm tuổi trên lát cắt nhĩ thạch. Chiều dài của cá ở các tuổi tương ứng xác định theo phương pháp tính ngược của Lea (1910) với công thức (5).

$$
F L_{i}=\frac{r_{1}}{H}=F L
$$

Trong đó: $\mathrm{FL}$ là chiều dài của cá $(\mathrm{cm}) ; \mathrm{FL}_{\mathrm{i}}$ là chiều dài của cá ở tuổi $\mathrm{i}(\mathrm{cm}) ; \mathrm{R}$ là kích thước bán kính nhĩ thạch $(\mu \mathrm{m}) ; \mathrm{r}_{\mathrm{i}}$ là kích thước bán kính nhĩ thạch ở vòng năm thứ $\mathrm{i}$ $(\mu \mathrm{m})$. 
Tốc độ sinh trưởng của cá được xác định với khoảng thời gian 1 năm theo công thức (2). Trong đó: $\Delta \mathrm{L} / \Delta \mathrm{t}$ là tốc độ sinh trưởng của cá $(\mathrm{cm} / \mathrm{năm}) ; \mathrm{L}_{\mathrm{i}}$ và $\mathrm{L}_{\mathrm{i}+1}$ là chiều dài thân cá $(\mathrm{FL})$ ở tuổi $\mathrm{i}$ và tuổi $\mathrm{i}+1(\mathrm{~cm}), \mathrm{t}_{\mathrm{i}}$ và $\mathrm{t}_{\mathrm{i}+1}$ là tuổi của cá ở năm $\mathrm{i}$ và năm $\mathrm{i}+1$ (năm).

$$
\frac{\Delta L}{\Delta t}=\frac{L_{i+1}-L_{i}}{t_{i+1}-t_{i}}
$$

Phương trình sinh trưởng Von Bertalanffy (3) được xác định dựa trên kết quả phân tích tuổi từ nhĩ thạch cá. Tham số $\mathrm{L}_{\infty}, \mathrm{k}$ được ược xác định bằng đồ thị Gulland and Holt (1959) theo công thức (4). Tham số $\mathrm{t}_{\mathrm{o}}$ xác định bằng phương pháp bình phương nhỏ nhất hoặc đồ thị Von Bertalanffy theo công thức (5) (Sparre, Venema, 1998).

$$
\begin{aligned}
& L_{z}=L_{w} *\left(1-e^{-k \leqslant\left(t-t_{0}\right)}\right) \\
& \frac{\Delta L}{\Delta t}=k * L_{n}-k * L_{t} \\
& t(L)=t_{0}-\frac{1}{k} * \operatorname{Ln}\left(1-L / L_{\infty}\right)
\end{aligned}
$$

Trong đó: $\mathrm{L}_{\mathrm{t}}$ là chiều dài của cá ở thời điểm $\mathrm{t} ; \mathrm{L}_{\infty}$ là chiều dài tối đa mà cá có thể đạt được; $\mathrm{k}$ là tham số sinh trưởng; $\mathrm{t}_{\mathrm{o}}$ là tuổi lý thuyết khi cá có chiều dài bằng $0 ; \Delta \mathrm{L} / \Delta \mathrm{t}$ là tốc độ sinh trưởng $(\mathrm{cm} / \mathrm{năm}) ; \bar{L}_{t}$ là chiều dài trung bình của hai nhóm tuổi liền kề $(\mathrm{cm}) ; \mathrm{t}(\mathrm{L})$ là tuổi của cá ở chiều dài L (năm).

Toàn bộ số liệu được xử lý bằng thống kê mô tả trên Microsoft Excel. Đo kích thước nhĩ thạch và kích thước vòng năm bằng phần mềm Image-Pro Express 6.0. Sử dụng phần mềm Photoshop 7.0 để xử lý hình ảnh. Sử dụng phần mềm Statistica 8.0 để xác định các hệ số tương quan và vẽ đồ thị.

\section{KẾT QUẢ VÀ THẢO LUẬN}

\section{1. Đặc điểm nhĩ thạch}

Nhĩ thạch cá miễn sành hai gai tương đối lớn, hình bầu dục, một đầu hơi nhọn và một đầu tròn (hình 4). Mặt lưng có rãnh lớn, uốn cong chạy dọc nhĩ thạch. Viền ngoài của nhĩ thạch có dạng răng cưa, lồi lõm không đều. Nhìn từ mặt lưng, cánh trái nhĩ thạch lõm sâu vào trong tạo thành phần khuyết ở góc phần tư thứ hai.

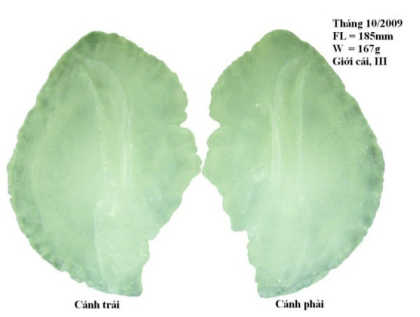

Hình 4: Hình thái nhĩ thạch của cá miễn sành hai gai ở vùng đánh cá chung VBB. 
Tổng số đã thu thập và phân tích được 174 mẫu nhĩ thạch của cá miễn sành hai gai ở vùng đánh cá chung VBB. Mẫu cá thu thập có chiều dài cơ thể dao động trong khoảng $10,7-24,5 \mathrm{~cm}$, tương ứng với khối lượng cơ thể khoảng 33,4 - 357,0g (bảng 1). Cá miễn sành hai gai là loài có kích thước nhĩ thạch tương đối lớn với chiều dài 5,381-10,641mm, chiều rộng 4,628-7,803mm và khối lượng tương ứng khoảng 31,6 - 168,2mg. Dựa trên dữ liệu đã thu thập, tương quan tuyến tính giữa chiều dài thân cá (FL) với chiều dài nhĩ thạch $(\mathrm{OL})$ và giữa chiều rộng nhĩ thạch $\left(\mathrm{OW}_{\mathrm{i}}\right)$ với chiều dài nhĩ thạch $(\mathrm{OL})$ được xác lập tương ứng theo các phương trình $\mathrm{FL}=-15,81+22,0 * \mathrm{OL}(\mathrm{R}=0,97 ; \mathrm{n}=174)$ và $\mathrm{OW}_{\mathrm{i}}=1,68+$ $0,55 * \mathrm{OL}(\mathrm{R}=0,96 ; \mathrm{n}=174)$ (hình 5 ). Tương tự như quá trình sinh trưởng của cơ thể, chiều dài nhĩ thạch và khối lượng nhĩ thạch $\left(\mathrm{OW}_{\mathrm{e}}\right)$ có mối tương quan theo hàm mũ khá chặt $\mathrm{OW}_{\mathrm{e}}=0,432 * \mathrm{OL}^{2,51}(\mathrm{R}=0,98 ; \mathrm{n}=174)$ (hình 5).

Bảng 1: Tổng hợp giá trị các chỉ số quan sát của mẫu nhĩ thạch đã phân tích

\begin{tabular}{|c|c|c|}
\hline Chỉ số mẫu quan sát $(N=174$ mẫu) & Khoảng dao động & Trung bình \\
\hline Chiều dài cá thể - FL $(\mathrm{cm})$ & $10,7-24,5$ & $14,7 \pm 0,79$ \\
\hline Khối lượng cơ thể - W (g) & $33,4-357,0$ & $89,4 \pm 1,16$ \\
\hline Chiều dài nhĩ thạch - OL (mm) & $5,381-10,641$ & $7,415 \pm 0,053$ \\
\hline Chiều rộng nhĩ thạch - $\mathrm{OW}_{\mathrm{i}}(\mathrm{mm})$ & $4,628-7,803$ & $5,776 \pm 0,402$ \\
\hline Khối lượng nhĩ thạch - $\mathrm{W}_{\mathrm{e}}(\mathrm{mg})$ & $31,6-168,2$ & $69,7 \pm 0,83$ \\
\hline
\end{tabular}

Hình 5: Biểu đồ tương quan giữa chiều dài thân cá với chiều dài nhĩ thạch, chiều dài nhĩ thạch với chiều rộng nhĩ thạch và chiều dài nhĩ thạch với khối lượng nhĩ thạch .

\section{Tuổi của cá}

Tuổi của cá được nghiên cứu dựa trên các vòng năm trên lắt cắt nhĩ thạch. Vòng năm sinh trưởng được xác định bằng sự kết hợp của một vùng mờ đục và một vùng sáng (Hou et al., 2008). Tùy thuộc mùa vụ sinh sản của loài mà sự hình thành các vùng là khác nhau. Cá 1 năm tuổi được xác định bởi sự kết hợp của một vùng sáng với tốc độ sinh trưởng nhanh và một vùng mờ đục với tốc độ sinh trưởng chậm. Hình dạng và sự hình 
thành vòng năm của cá miễn sành hai gai trình bày ở hình 6 . Bán kính nhĩ thạch được xác định từ tâm đến viền ngoài của nhĩ thạch. Ở loài cá này, bán kính nhĩ thạch dao động từ $1,869 \mathrm{~mm}$ đến $3,528 \mathrm{~mm}$, trung bình khoảng 2,624mm.

Tổng số 166 mẫu nhĩ thạch cá miễn sành hai gai được phân tích xác định tuổi. Chiều dài của cá ở các tuổi tương ứng được xác định trên tương quan giữa bán kính vòng năm, bán kính nhĩ thạch và chiều dài thân cá. Phân bố tần suất theo nhóm chiều dài ở từng nhóm tuổi được trình bày ở bảng 2. Các mẫu phân tích được thu ở nhiều thời điểm khác nhau, do vậy thành phần tỉ lệ trình bày ở bảng 2 không được xem là cấu trúc tuổi của quần thể nghiên cứu. Tỉ lệ thành phần ở đây chỉ đơn thuần mô tả cấu trúc mẫu thu thập và phân tích. Số cá thể bắt gặp trong quần đàn có chiều dài lớn hơn $17 \mathrm{~cm}$ tương đối ít, trung bình chiếm khoảng 2,0\% tổng số cá thể của quần đàn. Do vậy, các cá thể có kích thước lớn cần được thu thập bổ sung đảm bảo số mẫu cho từng nhóm chiều dài đạt mức có thể. Nhìn chung, cấu trúc tuổi của đàn cá miễn sành hai gai chủ yếu tập trung ở nhóm tuổi $0^{+}$đến tuổi $2^{+}$. Số lượng cá thể ở các nhóm tuổi lớn ít bắt gặp, nhóm tuổi $5^{+}$và $6^{+}$chỉ bắt gặp 1 cá thể trong thời gian nghiên cứu.

Bảng 2: Phân bố tần suất theo nhóm chiều dài và nhóm tuổi của cá miễn sành hai gai.

\begin{tabular}{|c|c|c|c|c|c|c|c|c|}
\hline \multirow{2}{*}{$\begin{array}{c}\text { Nhóm } \\
\text { chiều dài } \\
\text { (cm) }\end{array}$} & \multicolumn{7}{|c|}{ Nhóm tuổi (năm) } & \multirow{2}{*}{$\begin{array}{c}\text { Tổng } \\
\text { số (con) }\end{array}$} \\
\hline & $\mathbf{0}^{+}$ & $1^{+}$ & $2^{+}$ & $3^{+}$ & $4^{+}$ & $5^{+}$ & $6^{+}$ & \\
\hline $101-110$ & 5 & & & & & & & 5 \\
\hline $111-120$ & 22 & & & & & & & 22 \\
\hline $121-130$ & 21 & 1 & & & & & & 22 \\
\hline $131-140$ & 4 & 18 & & & & & & 22 \\
\hline $141-150$ & & 21 & & & & & & 21 \\
\hline $151-160$ & & 26 & 1 & & & & & 27 \\
\hline $161-170$ & & 8 & 6 & & & & & 14 \\
\hline $171-180$ & & & 11 & & & & & 11 \\
\hline $181-190$ & & & 6 & 2 & & & & 8 \\
\hline $191-200$ & & & & 7 & & & & 7 \\
\hline $201-210$ & & & & 2 & 1 & & & 3 \\
\hline $211-220$ & & & & & 1 & & & 1 \\
\hline $221-230$ & & & & & 1 & 1 & & 2 \\
\hline $231-240$ & & & & & & & - & - \\
\hline $241-245$ & & & & & & & 1 & 1 \\
\hline Số mẫu & 52 & 74 & 24 & 11 & 3 & 1 & 1 & 166 \\
\hline Tỷ lệ (\%) & 31,3 & 44,6 & 14,5 & 6,6 & 1,8 & 0,6 & 0,6 & 100,0 \\
\hline
\end{tabular}

Ghi chú: nhóm tuổi $1^{+}$gồm cá thể lớn hơn 1 tuổi và nhỏ hơn 2 tuổi; các nhóm khác tương tụ. 


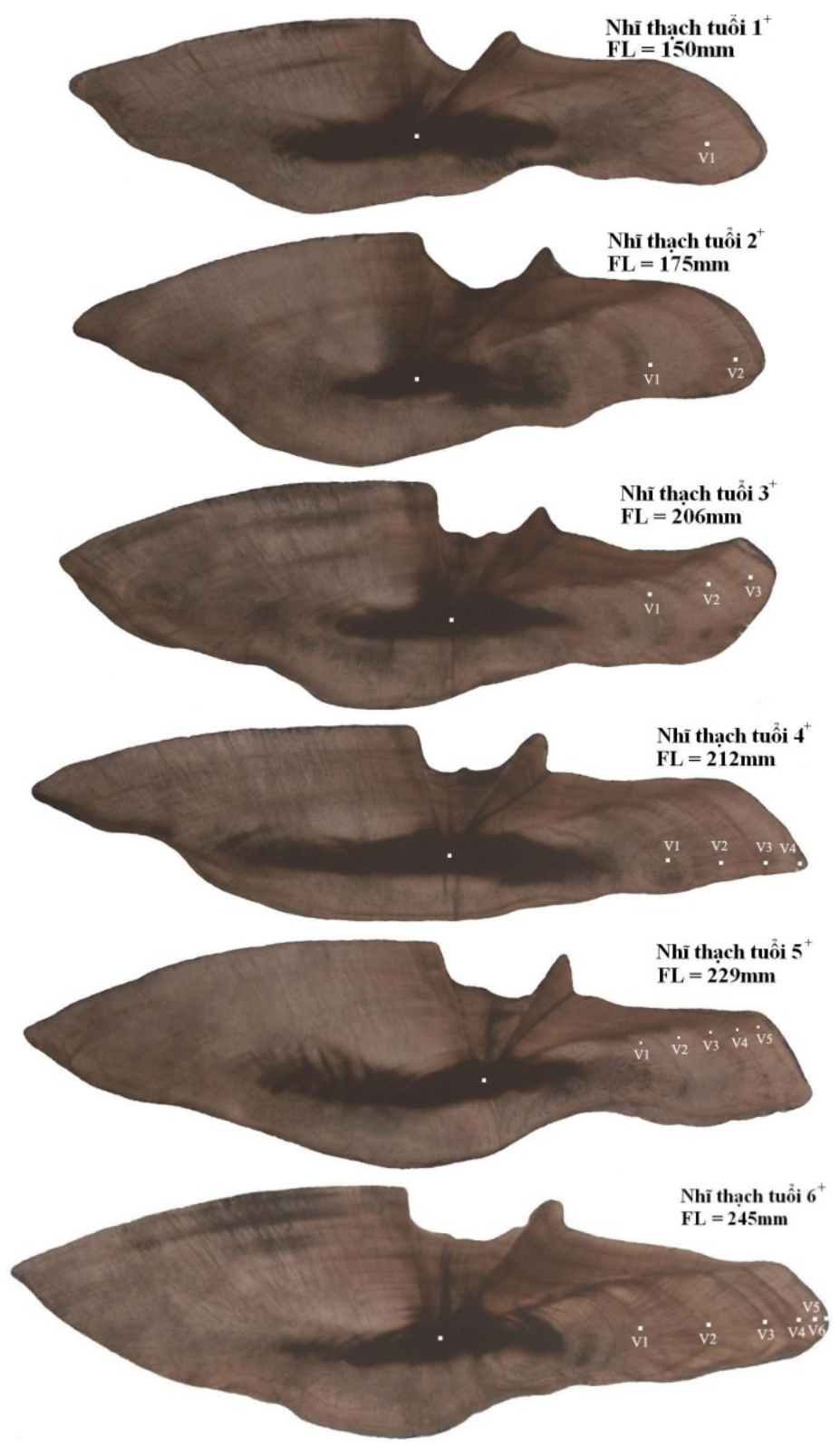

Hình 6: Hình dạng vòng năm trên nhĩ thạch cá miễn sành hai gai

Dựa trên kết quả phân tích nhĩ thạch đã xác định được chiều dài trung bình ở từng nhóm tuổi tương ứng, kết quả trình bày ở bảng 3 . Đàn cá 1 năm tuổi có chiều dài cơ thể dao động lớn, khoảng 10,5-13,1cm. Ở đàn cá lớn hơn 2 tuổi, khoảng chiều dài cơ thể ở các nhóm tuổi có xu hướng hẹp dần, cụ thể khoảng 15,1-16,7cm (2 tuổi), 17,7-19,2cm (3 tuổi), 19,9-21,7cm (4 tuổi) và 21,9-23,1cm (5 tuổi). Chiều dài trung bình theo tuổi được 
xác định dựa trên phân bố chiều dài ở từng nhóm tuổi (bảng 3). Cá 1 tuổi có chiều dài trung bình $11,9 \mathrm{~cm}$. Cá 2 tuổi có chiều dài trung bình $15,9 \mathrm{~cm}$. Cá 3 tuổi, 4 tuổi, 5 tuổi, 6 tuổi có chiều dài trung bình tương ứng là $18,5 \mathrm{~cm}, 20,9 \mathrm{~cm}, 22,5 \mathrm{~cm}$ và $23,5 \mathrm{~cm}$. Vòng năm trên nhĩ thạch xuất hiện tương đối rõ ràng, do vậy kết quả xác định tuổi cá tương đối chính xác. Mặc dù cá thể có kích thước lớn bắt gặp không nhiều nhưng không ảnh hưởng đến kết quả phân tích trong nghiên cứu này. Bởi vì, ở các cá thể có kích thước lớn việc xác định tuổi dễ dàng và đảm bảo độ chính xác cao hơn. Phương pháp này có ưu điểm hơn hẳn so với các phương pháp phân tách tần suất chiều dài.

Bảng 3: Tuổi và chiều dài trung bình theo tuổi của cá miễn sành hai gai

\begin{tabular}{|c|c|c|c|}
\hline Tuổi (năm) & $\begin{array}{c}\text { Khoảng chiều dài } \\
(\mathbf{c m})\end{array}$ & $\begin{array}{c}\text { Chiều dài trung bình } \\
(\mathbf{c m})\end{array}$ & Sai số chuẩn $(\mathbf{c m})$ \\
\hline 1 & $10,5-13,1$ & 11,9 & 0,1 \\
\hline 2 & $15,1-16,7$ & 15,9 & 0,1 \\
\hline 3 & $17,7-19,2$ & 18,5 & 0,2 \\
\hline 4 & $19,9-21,7$ & 20,9 & 0,6 \\
\hline 5 & $21,9-23,1$ & 22,5 & 1,2 \\
\hline 6 & $23,5^{*}$ & 23,5 & - \\
\hline
\end{tabular}

Ghi chú: (*) chỉ có 1 mẫu

\section{Phưong trình sinh trưởng Von Bertalanffy}
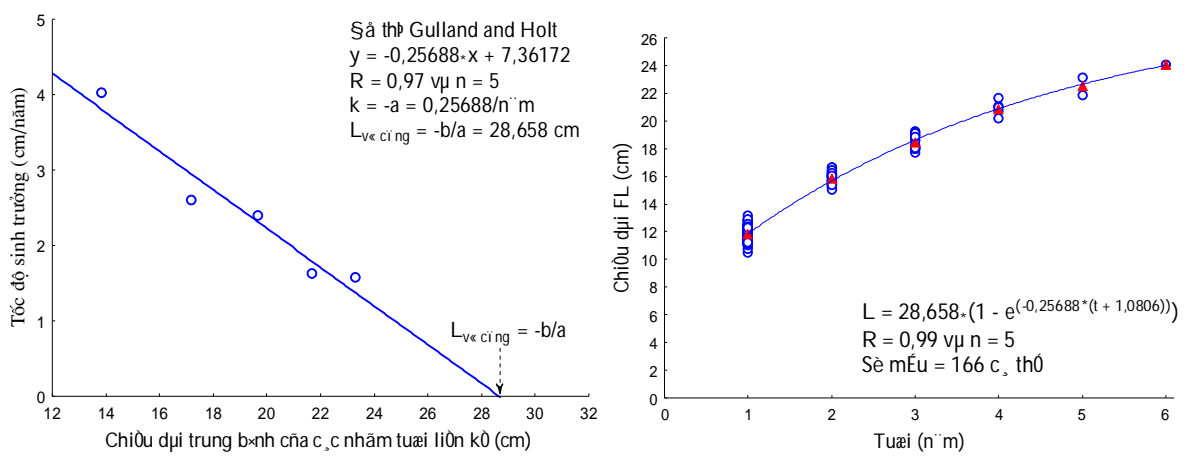

Hình 7: Biểu đồ Gulland and Holt (trái) và đường cong sinh trưởng Von Bertalanffy (phải) của cá miễn sành hai gai

Phương trình sinh trưởng von Bertalanffy của cá miễn sành hai gai ở Vùng đánh cá chung VBB được xác định dựa trên kết quả phân tích tuổi trên nhĩ thạch. Tham số chiều dài cực đại $\left(\mathrm{L}_{\infty}\right)$ và hệ số sinh trưởng $(\mathrm{k})$ được xác định bằng đồ thị Gulland and Holt, tuổi lý thuyết $\mathrm{t}_{\mathrm{o}}$ xác định bằng phương pháp bình phương nhỏ nhất, kết quả cụ thể trình bày ở hình 7. Phương trình sinh trưởng von Bertalanffy của cá miễn sành hai ở vùng biển nghiên 
cứu được xác định như sau: $\mathrm{FL}=28,66 *\left(1-\mathrm{e}^{(-0,257 *(t-(-1,08)))}\right)$. Hệ số sinh trưởng toàn phần $\emptyset$ được xác định với giá trị là 5,3 .

Bảng 4: Kết quả xác định các tham số trong phương trình sinh trưởng Von Bertalanffy ở các vùng biển lân cận.

\begin{tabular}{|c|c|c|c|c|c|c|c|}
\hline Vùng biển & $\begin{array}{c}\mathbf{L}_{\mathbf{m a}} \\
\mathbf{x} \\
(\mathbf{c m} \\
)\end{array}$ & $\begin{array}{l}\mathbf{L}_{\infty} \\
(\mathbf{c m})\end{array}$ & $\begin{array}{c}\mathbf{k} \\
(/ \mathbf{n a ̆ m} \\
)\end{array}$ & $\begin{array}{c}\mathbf{t}_{\mathbf{o}} \\
\text { (năm) }\end{array}$ & $\varnothing$ & $\begin{array}{c}\text { Số } \\
\text { mâ̂u }\end{array}$ & Tác giả \\
\hline Phía tây $V B B$ & 24,5 & 28,6 & 0,257 & $-1,080$ & $\begin{array}{r}5, \\
3\end{array}$ & 166 & Nghiên cứu này \\
\hline $\begin{array}{l}\text { Fujian, Đài } \\
\text { Loan }\end{array}$ & 20,0 & 27,3 & 0,174 & $-1,241$ & $\begin{array}{r}4, \\
9 \\
\end{array}$ & $\begin{array}{c}1.01 \\
9\end{array}$ & Zhang và Zhang (1983) \\
\hline $\begin{array}{l}\text { Fujian, Đài } \\
\text { Loan }\end{array}$ & - & 26,0 & 0,231 & - & $\begin{array}{r}5, \\
1 \\
\end{array}$ & - & Ye (2004) \\
\hline Phía đông VBB & 27,5 & 32,0 & 0,167 & $-1,116$ & $\begin{array}{r}5, \\
1 \\
\end{array}$ & $\begin{array}{c}1.15 \\
5\end{array}$ & $\begin{array}{l}\begin{array}{l}\text { Hou và dồng tác giả } \\
(2008)\end{array} \\
\end{array}$ \\
\hline
\end{tabular}

Ghi chú: (*) giá trị chiều dài đã được chuẩn hóa về cùng chiều dài FL; (-) không có số liệu

So sánh kết quả xác định các tham số trong phương trình sinh trưởng von Bertalanffy của các quần thể cá miễn sành khác nhau bằng phương pháp xác định tuổi trên nhĩ thạch và vảy được trình bày ở bảng 4 . Trong nghiên cứu này, tác giả sử dụng chiều dài đến chẽ vây đuôi (FL) đo kích thước cá nên không đồng bộ với các nghiên cứu trước. Do vậy, phương trình tương quan $\mathrm{FL}=1,061 * \mathrm{SL}+1,037\left(R^{2}=0,95 ; n=2511\right.$ cá thể $)$ được sử dụng để đồng bộ hóa các kết quả nghiên cứu trước nhằm thuận lợi cho quá trình so sánh. Kết quả xác định tham số $\mathrm{L}_{\infty}$ trong nghiên cứu này cao hơn so với nghiên cứu của Zhang và Zhang (1983) và Ye (2004) ở vùng biển Fujian, Đài Loan nhưng thấp hơn so với nghiên cứu của Hou và đồng tác giả (2008) ở vùng biển phía Đông VBB (bảng 4). Thông thường, kết quả xác định tham số $\mathrm{L}_{\infty}$ phụ thuộc lớn vào chiều dài cực đại $\left(\mathrm{L}_{\max }\right)$ bắt gặp. Ở $\mathrm{VBB}$, chiều dài lớn nhất bắt gặp trong nghiên cứu này nhỏ hơn so với nghiên cứu của Hou và đồng tác giả (2008), do vậy tham số $\mathrm{L}_{\infty}$ nhỏ hơn hoàn toàn có thể chấp nhận được. Tham số sinh trưởng $\mathrm{k}$ trong nghiên cứu này đạt giá trị cao hơn so với các nghiên cứu khác cho loài cá này ở vùng biển Fujian, Đài Loan và phía đông VBB. Tuy nhiên, hai tham số tham số $\mathrm{L}_{\infty}$ và $\mathrm{k}$ có mối quan hệ tương đối chặt và đặc trưng cho quần thể ở vùng biển nghiên cứu. Ở một quần thể, nếu chiều dài cực đại $\mathrm{L}_{\infty}$ càng lớn thì tham số sinh trưởng $\mathrm{k}$ là nhỏ và ngược lại. Do vậy, để so sánh hai hay nhiều quần đàn hoặc các kết quả nghiên cứu khác nhau, hệ số sinh trưởng toàn phần $\emptyset^{\prime}$ được sử dụng. Hệ số sinh trưởng toàn phần trong nghiên cứu này đạt giá trị cao nhất, tuy nhiên với mức chênh lệch không 
nhiều so với các kết quả nghiên cứu trong những năm gần đây của Hou và đồng tác giả (2008) và Ye (2004).

Đường cong phương trình sinh trưởng von Bertalanffy của cá miễn sành hai gai ở các nghiên cứu khác nhau được mô phỏng và trình bày ở hình 8 . Nhìn chung, đường cong sinh trưởng xác định cho quần thể loài cá này ở vùng biển phía Tây VBB cao hơn so với các kết quả nghiên cứu khác. Như vậy, ở cùng một nhóm tuổi, chiều dài trung bình của đàn cá ở vùng biển này có kích thước lớn hơn so với các đàn cá ở các vùng biển lân cận.

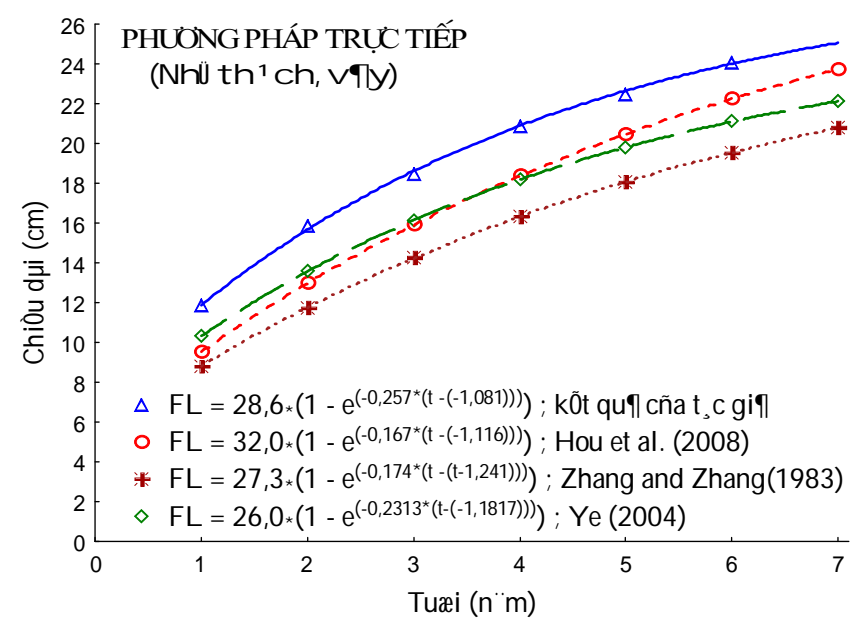

Hình 8: Đường cong von Bertalanffy của cá miễn sành hai gai ở các vùng biển khác nhau.

\section{Tốc độ sinh trưởng}

Sinh trưởng là quá trình gia tăng kích thước cơ thể theo tuổi. Tốc độ sinh trưởng là lượng gia tăng về kích thước cơ thể qua các năm trong chu kỳ sống. Nhìn chung, tốc độ sinh trưởng của cá miễn sành hai gai phản ánh quy luật đặc thù sinh trưởng của sinh vật. Cơ thể sinh trưởng nhanh ở năm đầu và đạt chiều dài trung bình khoảng $11,9 \mathrm{~cm}$. Ở những năm tiếp theo, tốc độ sinh trưởng chậm dần với mức chênh lệch giữa các năm không nhiều, tương ứng khoảng $3,8 \mathrm{~cm}$ ở năm thứ hai, $2,9 \mathrm{~cm}$ ở năm thứ $\mathrm{ba}, 2,3 \mathrm{~cm}$ ở năm thứ tư và $1,8 \mathrm{~cm}$ ở năm thứ năm. Xu hướng biến động tốc độ sinh trưởng của cá miễn sành hai gai qua các năm tương đối đồng pha ở các nghiên cứu khác nhau (hình 9). Tuy nhiên, tốc độ sinh trưởng trong nghiên cứu này cao hơn so với kết quả nghiên cứu của Zhang và Zhang (1983), Ye (2004) và Hou và đồng tác giả (2003) ở 3 năm đầu của chu kỳ sống (bảng 5). 


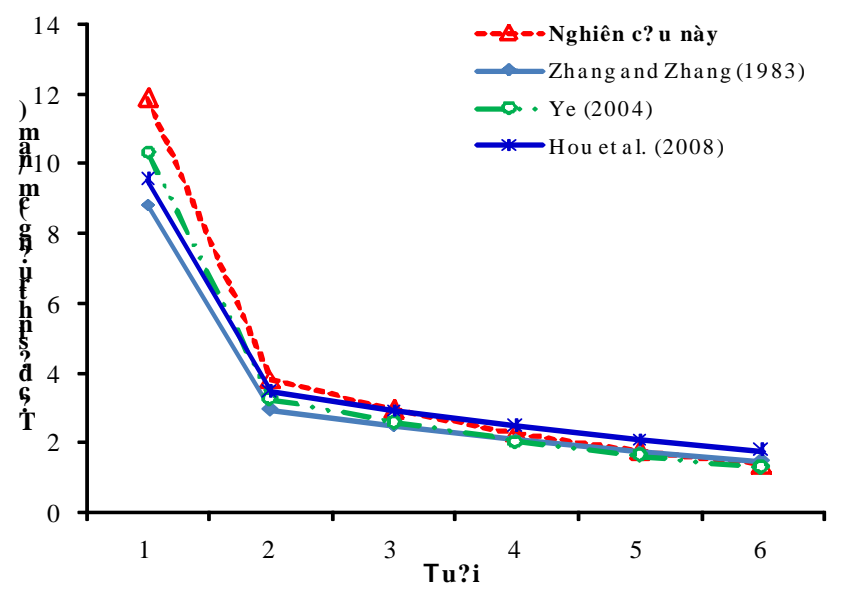

Hình 9: Biểu đồ tốc độ sinh trưởng của cá miễn sành hai gai ở các nghiên cứu khác nhau

Bảng 5: Tốc độ sinh trưởng của cá miễn sành hai gai ở các nghiên cứu khác nhau

\begin{tabular}{|c|c|c|c|c|c|c|c|}
\hline \multirow[t]{2}{*}{ Vùng biển } & \multicolumn{6}{|c|}{$\begin{array}{l}\text { Tốc độ sinh trưởng theo năm } \\
\qquad(\mathrm{cm} / \mathrm{năm})\end{array}$} & \multirow[t]{2}{*}{ Tác giả } \\
\hline & N1 & $N 2$ & N3 & N4 & N5 & N6 & \\
\hline Phía tây VBB & $\begin{array}{c}11, \\
9\end{array}$ & 3,8 & 2,9 & 2,3 & 1,8 & 1,4 & Nghiên cúu này \\
\hline Fujian, Đài Loan & 8,8 & 3,0 & 2,5 & 2,1 & 1,8 & 1,5 & Zhang và Zhang (1983) \\
\hline Fujian, Đài Loan & $\begin{array}{c}10, \\
3\end{array}$ & 3,2 & 2,6 & 2,0 & 1,6 & 1,3 & Ye $(2004)^{*}$ \\
\hline Phía đông VBB & 9,5 & 3,5 & 2,9 & 2,5 & 2,1 & 1,8 & $\begin{array}{l}\text { Hou và đồng tác giả } \\
\qquad(2008)^{*}\end{array}$ \\
\hline
\end{tabular}

Ghi chú: (*) các giá trị đã được chuẩn hóa về cùng chiều dài FL; N1 là năm thú nhất.

\section{KẾT LUẬN VÀ ĐỀ XUẤT}

Nhĩ thạch cá miễn sành hai gai có kích thước lớn. Vòng năm trên nhĩ thạch cá thể hiện tương đối rõ. Cá thể lớn nhất bắt gặp ở vùng biển này thuộc nhóm tuổi $6^{+}$. Cấu trúc tuổi của đàn cá chủ yếu tập trung ở nhóm tuổi $0^{+}$đến tuổi $2^{+}$. Phương trình sinh trưởng von Bertalanffy của cá miễn sành hai gai có dạng $\mathrm{L}=28,66 *\left(1-\mathrm{e}^{\left(-0,257^{*}(\mathrm{t}-(-1,08))\right)}\right)$. Cá thể sinh trưởng nhanh ở năm đầu và chậm dần với mức chênh lệch không nhiều ở những năm tiếp theo. 


\section{TÀI LIỆU THAM KHẢO}

1. Chen, Z. J. and Qui, Y. S., 2003. "Esitimation of growth and mortality parameters of Parargyrops edita Tanaka in Beibu Bay (Chinese with English abstract)", Jounal of Fisheries of China 27(3), pp.251-257.

2. Chen, Z. J. and Qiu, Y. S., 2005. "Ecological distribution of Paragyrops edita Tanaka in the Beibu Gulf (Chinese with English abstract)", Marine Fisheries Research, 26, pp.16-21

3. Chu Tiến Vĩnh, 2002. Điều tra nguồn lợi hải sản ven bờ vịnh Bắc bộ, Viện Nghiên cứu Hải sản, Hải Phòng, 40tr.

4. Đào Mạnh Sơn, 2001. "Nguồn lợi hải sản xa bờ vịnh Bắc bộ, Đông Nam bộ và vùng biển giữa biển Đông của Việt Nam", Tuyển tập nghiên cứu nghề cá biển, Tập II, tr.147-174.

5. Eggleston, D., 1974. Sparidae. In W. Fischer and P.J.P. Whitehead (eds.) FAO species identification sheets for fishery purposes. Eastern Indian Ocean (Fishing Area 57) and Western Central Pacific (Fishing Area 71), Volume 4, FAO, Rome.

6. Gulland, J.A. and Holt, S. J., 1959. "Estimate of growth parameters for dat at uenqual time intervals", J. Cons. CIEM, 25(1), pp.47-49.

7. Hou, G., Feng, B., Lu, H., and Zhu, J., 2008. "Age and Growth Characteristics of Crimson Sea Bream Paragyrops edita Tanaka in Beibu Gulf", Jounal of Ocean University of China, 7(4), pp.457-465.

8. Lea, E., 1910. "On the method used in herring investigations", Puplications de Circonstance. Conseil Intenational pour L'Exploration de la Mer, 108(1), pp.14-22.

9. Masuda, H., Amaoka, K., Araga, C., Uyeno, T., and Yoshino, T., 1984. The fishes of the Japanese Archipelago, Vol. 1, 437p, Tokai University Press, Tokyo, Japan.

10. Nguyễn Hữu Phụng, Lê Trọng Phấn, Nguyễn Nhật Thi, Nguyễn Phi Đính, Đỗ Thị Như Nhung và Nguyễn Văn Lục, 1995. Danh muc cá biển Việt Nam, Tập III, tr. 359-360, Nhà xuất bản Khoa học và Kỹ thuật, Hà Nội.

11. Phạm Thược, Nguyễn Công Con, Đoàn Văn Dư, Phạm Tuyên, Trần Bình Đoạn, Phạm Văn Thành, Nguyễn Duy Hồng, and Nguyễn Thị Nga, 1977. Tình hình 
nguồn lợi và ước tính trũ lương cá tầng đáy vịnh Bắc bộ, 81 tr., Viện Nghiên cứu Hải sản, Hải Phòng.

12. Sparre, P. and Venema, S. C., 1998. Introduction to tropical fish stock assessment Part 1: Manual, 407p, FAO Fisheries Technical Paper. No. 306/1, Rev.2, Rome, Italy.

13. Stevenson, D. K. and Campana, S. E., 1992. Otolith microstructure examination and analysis, 117, 130p, Can. Spec. Publ. Fish. Aquat. Sci.

14. Vũ Việt Hà, 2008. "Đặc trưng phân bố, biến động nguồn lợi một số loài cá đánh được bằng lưới kéo đáy ở vùng biển phía Tây vịnh Bắc bộ", Tuyển tập nghiên cứu nghè̀ cá biển, Tập V, tr: 99-109.

15. Ye, S. Z., 2004. "Growth characteristics of golden-skin porgy, Parargyrops edita, in the south Fujian and Taiwan bank fishing ground (Chiense with English abstract)", Journal of Fisheries of China, 28, pp.663-668.

16. Zhang, Q. Y. and Zhang, Y. Z., 1983. "Age and growth of red-fin pargo Paragyrops edita Tanaka in south Fujian and Taiwwan bank fishing ground (Chinese with English abstract)", Journal of Fisheries of China, 2.

\title{
AGE AND GROWTH OF THREADFIN PORGY (EVYNNIS CARDINALIS LACEPÈDE, 1802) IN THE WESTERN PART OF THE TONKIN GULF
}

\section{TRAN VAN CUONG}

\begin{abstract}
Summary: Data on sagittal otolith collected in periods from 2009 to 2011 in the western part of the Tonkin Gulf were used to analyse age and growth of Threadfin. Results indicated that the otolith of Threadfin Porgy is large with the year rings are clearly seen. Population structure of Threadfin Porgy was dominanted by the fish group of $0^{+}$to $3^{+}$and the biggest fish sampled to be $6^{+}$. The von Bertalanffy growth function for Threadfin Porgy was estimated as follows $F L=28,66 *\left(1-e^{\left(-0,257^{*}(t-(-1,08))\right)}\right)$.
\end{abstract}

Keywords: Age and growth, Evynnis cardinalis, Tonkin Gulf, Threadfin Porgy.

Ngày nhận bài: 24 - 8 - 2011

Người nhận xét: PGS. TS. Lê Trọng Phấn 